\title{
Design of hydrogen storage alloys with the aid of molecular orbital method
}

\author{
H YUKAWA, M TAKAGI and M MORINAGA* \\ Department of Materials Science and Engineering, Graduate School of Engineering, Nagoya University, Furo-cho, \\ Chikusa-ku, Nagoya 464-8603, Japan
}

\begin{abstract}
The electronic structures of hydrogen storage alloys are calculated by the DV-X $\alpha$ molecular orbital method. The results revealed that hydrogen interacts more strongly with hydride-non-forming elements, $B$, (e.g. $\mathrm{Ni}, \mathrm{Mn}, \mathrm{Fe}$ ) than hydride-forming elements, A, (e.g. La, Zr, Ti, Mg) in every hydrogen storage alloy, despite there being a larger affinity of A elements for hydrogen than B elements in the binary metal-hydrogen system. The presence of such a metal-hydrogen interaction is a characteristic of hydrogen storage alloys. Furthermore, the $A / B$ compositional ratio of hydrogen storage alloys can be understood in terms of a simple parameter, $2 B o(A-B) /[B o(A-A)+B o(B-B)]$, where the $B o(A-B), B o(A-A)$ and $B o(B-B)$ are the bond orders between atoms given in the parentheses.
\end{abstract}

Keywords. Electronic structure; hydrogen storage alloys; hydrides; LaNi $; \mathrm{ZrMn}_{2} ; \mathrm{Mg} \mathbf{N i}$ TiFe; $\mathrm{V}$ alloys.

\section{Introduction}

Hydrogen storage alloys are important materials for the future development of clean hydrogen energy system. A variety of hydrogen storage alloys have been developed and their alloying effects have been experimentally investigated to further improve their hydriding properties. On the basis of these extensive studies, several empirical rules have been formulated which have been used for the development of hydrogen storage alloys, although there are exceptions to the rules. However, the total amount of hydrogen stored in any alloys is still low from the point of its practical applications. Therefore, an alternative approach is required to understand the hydriding properties of these alloys as well as their alloying effects.

Recently, we have investigated the alloying effects of the typical hydrogen storage alloys on their electronic structure, for example of the alloys $\mathrm{LaNi}_{5}$ (Yukawa et al 1996), $\mathrm{ZrMn}_{2}$ (Matsumura et al 1998), TiFe (Yukawa et al 1999), $\mathrm{Mg}_{2} \mathrm{Ni}$ (Takahashi et al 1996) and b.c.c.V (Matsumura et al 1999), all containing various alloying elements. Our investigations revealed that the stability of hydride formed in these alloys can be understood in terms of (i) the nature of the chemical bond between atoms in a small polyhedron where hydrogen is stored, and (ii) the crystal structural evolution during hydrogenation (Yukawa et al 1997). In this paper we have reviewed the recent findings on designing of hydrogen storage alloys, which were obtained by the DV-X $\alpha$ molecular orbital calculation.

*Author for correspondence

\section{DV-X $\alpha$ cluster method and cluster models}

The DV-X $\alpha$ cluster method is a molecular orbital method, assuming a Hartree-Fock-Slater (HFS) approximation, that gives accurate calculations of local electronic structures around hydrogen. In this method, the exchange-correlation between electrons, $V_{\mathrm{XC}}$, is given by the following Slater's X $\alpha$ potential:

$$
V_{\mathrm{xC}}=-3 \alpha\left[\frac{3}{8 \pi} \rho(r)\right]^{1 / 3} \text {, }
$$

where $\rho(r)$ is the density of electrons at position $r$, the parameter $\alpha$ is fixed at 0.7 and the self-consistent charge approximation is used in this calculation. The matrix elements of Hamiltonian and the overlap integrals are calculated by a random sampling method. The molecular orbitals are constructed by a linear combination of numerically generated atomic orbitals (LCAO).

Depending on the crystal structure, appropriate cluster models are employed in the calculation. Here, 'cluster' means a hypothetical molecule to represent a bulk crystal. For example, a cluster model used for the $\mathrm{LaNi}_{5}$ system is shown in figure 1. This is constructed on the basis of the crystal structure of $\mathrm{LaNi}_{5} \mathrm{H}_{6}$ hydride.

For a characterization of the electronic structure, the spatial electron density distributions, the bond order between atoms and ionicities of each atom in the cluster are estimated according to the Mulliken (1955) population analysis. Further detailed explanation of the calculation method is given elsewhere (Adachi et al 1978, 1979; Morinaga et al 1984, 1985, 1987). 


\section{Electronic structure of hydrogen-storage alloys}

\subsection{Chemical bonding state of hydrogen}

Hydrogen-storage alloys such as $\mathrm{LaNi}_{5}\left(\mathrm{AB}_{5}\right.$-type), $\mathrm{ZrMn}_{2}$ ( $\mathrm{AB}_{2}$-type), TiFe (AB-type) and $\mathrm{Mg}_{2} \mathrm{Ni}\left(\mathrm{A}_{2} \mathrm{~B}\right.$-type) are comprised of hydride-forming (A), and hydride-nonforming (B) elements. While the role of the hydride forming element (e.g. La) may be speculated for resulting in forming a strong chemical bond with hydrogen, the role of hydride-non-forming element (e.g. Ni) can be considered for reducing such a strong $\mathrm{A}-\mathrm{H}$ bond so that hydrogen is released readily from the $A$ atom in the hydrogen desorption process. However, Yukawa et al (1996), Takahashi et al (1996), and Matsumura et al (1998) have refuted these speculations as being too naive.

Figure 2 shows the contour map of the electron densities on the lattice plane, in the $\mathrm{LaNi}_{5}$ system, where all the $\mathrm{La}, \mathrm{Ni}$, and $\mathrm{H}$ atoms lie. The relatively high electron-density region near hydrogen extends towards the $\mathrm{Ni}$ atom site, but not towards the La atom site. This clearly indicates that hydrogen has a greater affinity for $\mathrm{Ni}$ atoms than $\mathrm{La}$ atoms in the $\mathrm{LaNi}_{5}$ system (Yukawa et al 1996). Similar results have been obtained for $\mathrm{ZrMn}_{2}$ system (Matsumura et al 1998), $\mathrm{Mg}_{2} \mathrm{Ni}$ system (Takahashi et al 1996), and TiFe system (Yukawa et al 1999) as well, where hydrogen atoms interact more strongly with $B$ atoms $(\mathrm{Mn}, \mathrm{Ni}$ or $\mathrm{Fe})$ rather than with the $\mathrm{A}$ atoms $(\mathrm{Zr}$, $\mathrm{Mg}$ or $\mathrm{Ti})$.

However, this $\mathrm{B}-\mathrm{H}$ (e.g. $\mathrm{Ni}-\mathrm{H}$ ) interaction in the hydride (e.g. $\mathrm{LaNi}_{5} \mathrm{H}_{6}$ ) is still weaker compared to the A-H (e.g. La-H) interaction in the pure metal hydride, $\mathrm{AH}_{2}$, (e.g. $\mathrm{LaH}_{2}$ ). For example, on comparison of the heat of formation, $\Delta H$, between $\mathrm{LaH}_{2}$ and $\mathrm{LaNi}_{5} \mathrm{H}_{6}$ (figure 3), $\Delta H$ is $-209.2 \mathrm{~kJ} / \mathrm{mol} \mathrm{H}_{2}$ for $\mathrm{LaH}_{2}$ and $-30.1 \mathrm{~kJ} / \mathrm{mol} \mathrm{H}$ for $\mathrm{LaNi}_{5} \mathrm{H}_{6}$. As explained above, the $\mathrm{Ni}-\mathrm{H}$ interaction is stronger than the $\mathrm{La}-\mathrm{H}$ interaction in the $\mathrm{LaNi}_{5}$ system, but this $\mathrm{Ni}-\mathrm{H}$ interaction is supposed to be weaker

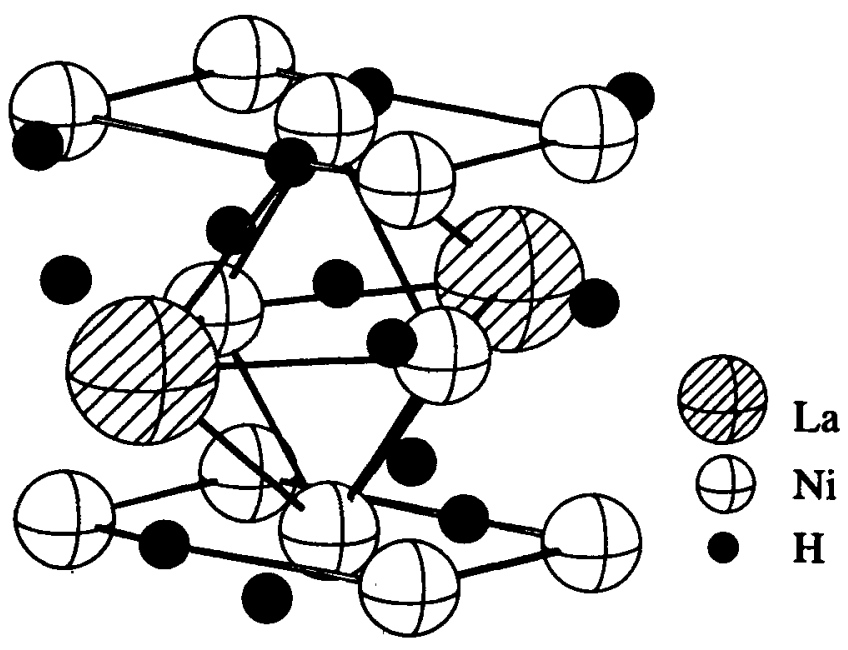

Figure 1. Cluster model used in the calculation for $\mathrm{LaNi}_{5}$ system. compared to the $\mathrm{La}-\mathrm{H}$ interaction in $\mathrm{LaH}_{2}$, judging from the magnitude of the heat of formation of the two hydrides (figure 3). The hydrogen desorption process can thus be activated readily because of weak interactions with hydrogen operating in hydrogen storage alloys (Yukawa et al 1997). On the other hand, $\mathrm{LaH}_{2}$ is too stable to be dehydrided at moderate temperatures. In this sense, it may be said that the existence of weak metal-hydrogen interactions is the characteristic of hydrogen storage alloys.

\subsection{Roles of hydride-forming and hydride-non-forming elements}

However, the hydride-forming element (A) does play an important role in the formation of the $\mathrm{B}-\mathrm{H}$ bond (Nakatsuka et al 1999). In order to make clear the roles of

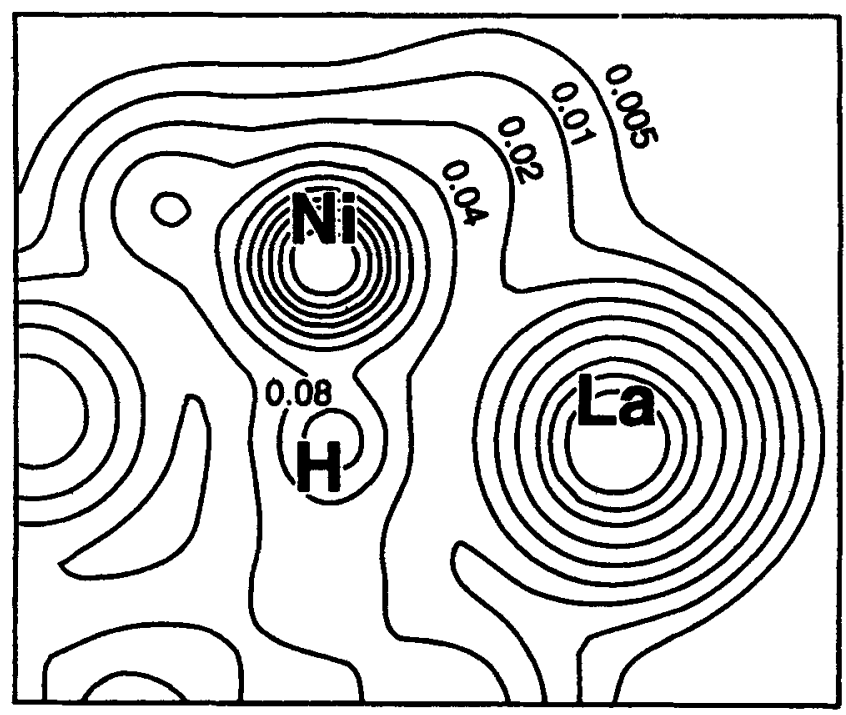

Figure 2. Contour map of the electron densities in $\mathrm{LaNi}_{5}$ system. The denoted numbers indicate the numbers of electron per a.u. ${ }^{3}$ ( 1 a.u. $\left.=0.0529 \mathrm{~nm}\right)$.

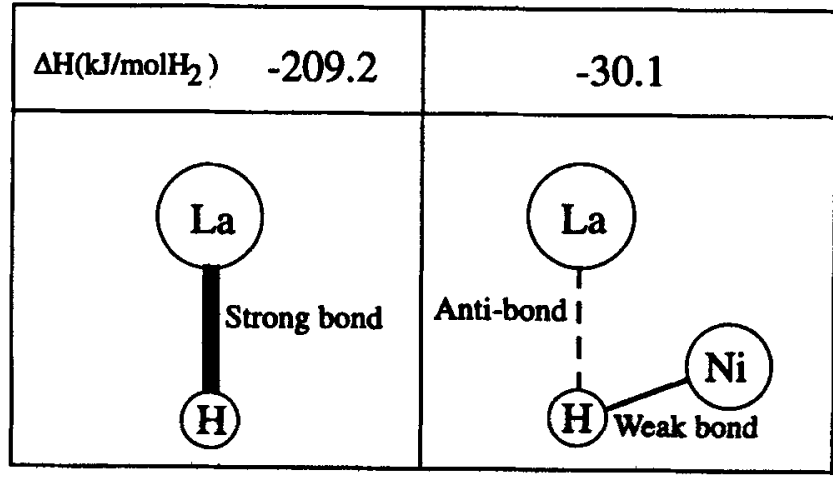

(a) $\mathrm{LaH}_{2}$

(b) $\mathrm{LaNi}_{5} \mathrm{H}_{6}$

Figure 3. Schematic illustration of metal-hydrogen interactions in a. $\mathrm{LaH}_{2}$, and b. $\mathrm{LaNi}_{5} \mathrm{H}_{6}$. 
hydride-forming and hydride-non-forming elements in hydrogen-storage alloys, a series of calculations of the electronic structures are carried out, using a Ni-based octahedral cluster, $\mathrm{M}_{2} \mathrm{Ni}_{4} \mathrm{H}$, (inset in figure 4), where $\mathrm{Ms}$ are various elements presented on the horizontal axis. From this figure, it is evident that the $\mathrm{Ni}-\mathrm{H}$ bond order is large when the $\mathrm{M}-\mathrm{H}$ bond order is small. In particular, the $\mathrm{Ni}-\mathrm{H}$ bond order is enhanced when $\mathrm{Ms}$, for example $\mathrm{Na}$, $\mathrm{Sr}$, and $\mathrm{Ba}$, are the hydride-forming elements. This means that hydrogen interacts strongly with $\mathrm{Ni}$ atoms if the hydride-forming elements exist in the neighbourhood, in agreement with the previous calculations of electronic structures of $\mathrm{Ni}$-containing hydrides (Takahashi et al
1996; Yukawa et al 1996). On the other hand, when Ms, for example $\mathrm{Fe}, \mathrm{Co}$, and $\mathrm{Ni}$, are the hydride-non-forming elements, the $\mathrm{Ni}-\mathrm{H}$ bond order is very small. Thus, it is apparent from figure 4 that the magnitude of the $\mathrm{Ni}-\mathrm{H}$ bond order correlates well with the heat of hydride formation of $\mathrm{M}$ metal or the heat of hydrogen dissolution in $\mathrm{M}$ metal.

Similar results are also obtained for the Ti-based octahedral cluster, $\mathrm{M}_{2} \mathrm{Ti}_{4} \mathrm{H}$. Here $\mathrm{Ti}$ is a hydride-forming element, in contrast to the hydride-non-forming element, $\mathrm{Ni}$, in the $\mathrm{M}_{2} \mathrm{Ni}_{4} \mathrm{H}$ cluster. As shown in figure 5 , when $\mathrm{Ms}$, for example $\mathrm{Fe}, \mathrm{Co}$, and $\mathrm{Ni}$, are the hydride-nonforming elements, the $\mathrm{Ti}-\mathrm{H}$ bond order is smaller than the

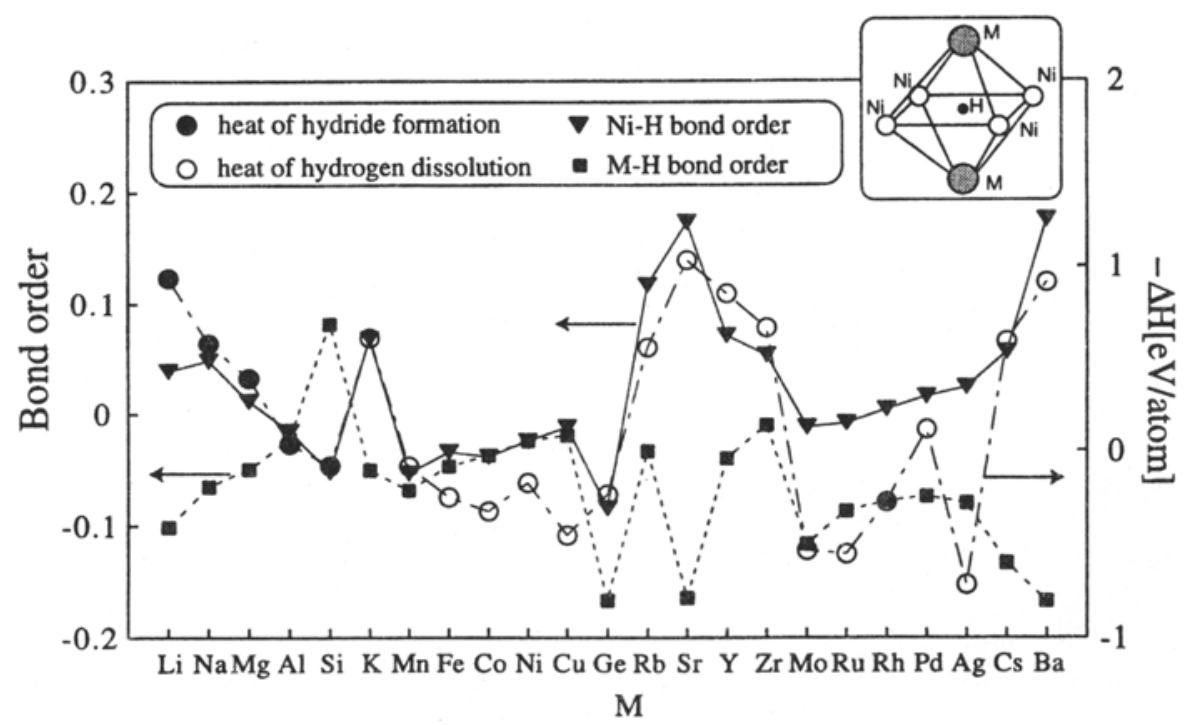

Figure 4. Bond orders between $\mathrm{Ni}$ and $\mathrm{H}$ atoms and between $\mathrm{M}$ and $\mathrm{H}$ atoms in the $\mathrm{HM}_{2} \mathrm{Ni}_{4}$ cluster, and comparison with the heat of hydride formation of $\mathrm{M}$ metal or the heat of hydrogen dissolution in $\mathrm{M}$ metal.

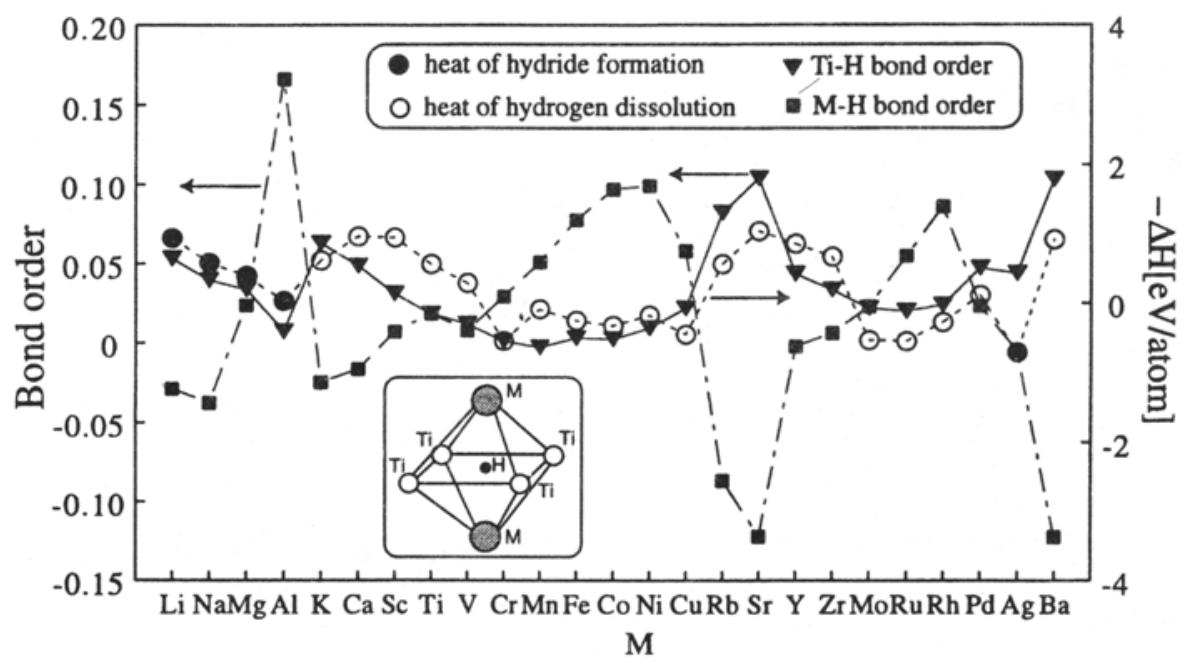

Figure 5. Bond orders between $\mathrm{Ti}$ and $\mathrm{H}$ atoms and between $\mathrm{M}$ and $\mathrm{H}$ atoms in the $\mathrm{HM}_{2} \mathrm{Ti}_{4}$ cluster, and comparison with the heat of hydride formation of $\mathrm{M}$ metal or the heat of hydrogen dissolution in $\mathrm{M}$ metal. 
M-H bond order. When Ms are stronger hydride-forming elements than $\mathrm{Ti}$, for example $\mathrm{Sr}, \mathrm{Y}$ and $\mathrm{Ba}$, the $\mathrm{Ti}-\mathrm{H}$ bond order is larger than the $\mathrm{M}-\mathrm{H}$ bond order. As a result, the $\mathrm{Ti}-\mathrm{H}$ bond order curve resembles the $-\Delta H$ curve as shown in figure 5. Similar results are also obtained for the Mg-based octahedral cluster, $\mathbf{M}_{2} \mathbf{M g}_{4} \mathrm{H}$. Therefore, there is a general trend that the B-H bond becomes strong only when the hydride-forming element (A) exists adjacent to $B$ and $H$ atoms. Otherwise, it remains weak or even antibonding, meaning that it is difficult for hydrogen to be absorbed in the alloy. Thus, both the hydride-forming and hydride-non-forming elements are essential elements in hydrogen-storage alloys.

\subsection{Criteria for alloy design}

In this section, some criteria for the design of hydrogen storage alloys will be discussed. For the design of new alloys, it is important first to select the constituent elements and then to determine the alloy composition.

3.3a Optimum atomic arrangements on metal polyhedra: As mentioned before, the constitution of both the hydride-forming elements (A) and hydride-non-forming elements (B) is essential for hydrogen-storage alloys, since, the presence of the B-H interaction is a characteristic of hydrogen storage alloys, and this interaction is enhanced only when the A elements exist near the $B$ elements in the alloy. Also, the effective number of the B-H bonds should increase when the concentration of $A$ element is high, on the basis of the results shown in figures 4 and 5 . As a result, the amount of hydrogen absorbed in the alloy should increase with increasing the $\mathrm{A} / \mathrm{B}$ compositional ratio. However, a disproportionation reaction tends to take place if the concentration of A element is too high in the alloy. This can be explained by assuming that there are three types of

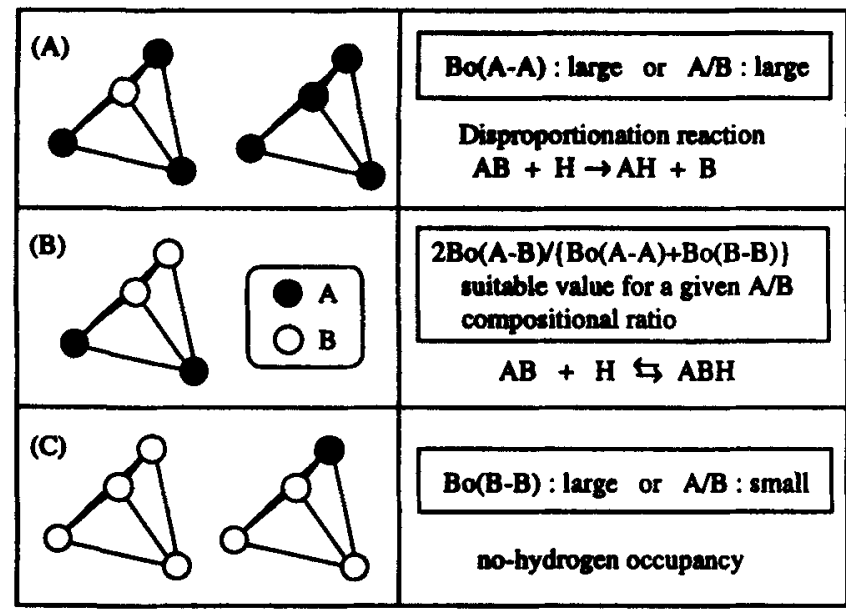

Figure 6. Relation between tetrahedral clusters and hydriding reactions. tetrahedral clusters in the A-B binary alloy, as shown in figure 6. Here, if the $A / B$ compositional ratio is high, or the $\mathrm{A}-\mathrm{A}$ bond is stronger than the A-B or the B-B bond, the clusters shown in figure $6 \mathrm{a}$ are dominant in the alloy. In such a case, hydrogen will interact mainly with the A elements upon introduction of hydrogen into the alloy, thereby resulting in the formation of strong $\mathrm{A}-\mathrm{H}$ bonds. Furthermore, the disproportionation reaction, $\mathrm{AB}+\mathrm{H} \rightarrow$ $\mathrm{AH}+\mathrm{B}$, will readily takes place in such a case. Here, $\mathrm{AH}$ is so stable in that the onset of this reaction is undesirable in view of the hydrogen desorption.

In contrast, when the $\mathrm{A} / \mathrm{B}$ compositional ratio is low, or the $\mathrm{B}-\mathrm{B}$ bond is stronger than the $\mathrm{A}-\mathrm{A}$ or the $\mathrm{A}-\mathrm{B}$ bonds, the clusters shown in figure $6 c$, are dominant in the alloy. In this case, it is very hard for hydrogen to be absorbed in such a B-atom-abundant cluster.

Therefore, in order to absorb and desorb hydrogen smoothly without the onset of any disproportionation reaction, the A/B compositional ratio has to be appropriately controlled, depending on the chemical bond strength between the A and the B elements, as shown in figure $6 \mathrm{~b}$. In other words, optimum clusters are formed in the alloy only when the bond order ratio, $2 \mathrm{Bo}(\mathrm{A}-$ $\mathrm{B}) /[\mathrm{Bo}(\mathrm{A}-\mathrm{A})+\mathrm{Bo}(\mathrm{B}-\mathrm{B})]$, takes a suitable value for a given $A / B$ compositional ratio.

3.3b Alloy compositions: A series of calculations were carried out to obtain the bond order ratio, $2 \mathrm{Bo}(\mathrm{A}-\mathrm{B}) /$ $[B o(A-A)+B o(B-B)]$, for various alloy systems using the tetrahedral clusters and the results are shown in figure 7. Here, this bond order ratio has a physical meaning similar to the interaction parameter, $\boldsymbol{\Omega}_{\mathrm{AB}}$ $\left(=V_{\mathrm{AB}}-1 / 2\left(V_{\mathrm{AA}}+V_{\mathrm{BB}}\right)\right)$, where $V_{\mathrm{AB}}, V_{\mathrm{AA}}, V_{\mathrm{BB}}$ are the respective bond strengths between the atoms given in the subscript. As described earlier, if this bond order ratio has a suitable value for a given alloy composition, the hydrogen absorption and desorption reaction,

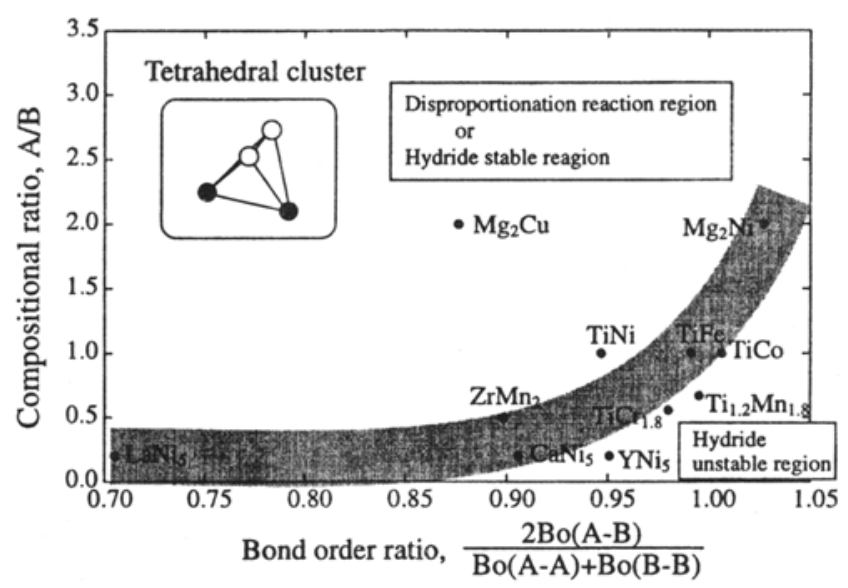

Figure 7. Correlation between the A/B compositional ratio and the bond order ratio for tetrahedral cluster. 
$\mathrm{AB}+\mathrm{H} \leftrightarrows \mathrm{ABH}$, is expected to take place readily in the alloy. In fact, as shown in figure 7 , there exists a strong correlation between the $\mathrm{A} / \mathrm{B}$ compositional ratio and the bond order ratio. For example, all the typical hydrogen storage alloys, e.g. $\mathrm{LaNi}_{5}, \mathrm{ZrMn}_{2}, \mathrm{TiFe}$, and $\mathrm{Mg}_{2} \mathrm{Ni}$, locate on a narrow band.

Furthermore, all the alloys located in the upper region above this narrow band (e.g. $\mathrm{Mg}_{2} \mathrm{Cu}$ ) tend to decompose during hydrogenation. For example, in case of $\mathrm{Mg}_{2} \mathrm{Cu}$, the disproportionation reaction, $\mathrm{Mg}_{2} \mathrm{Cu}+2 \mathrm{H}_{2} \rightarrow 2 \mathrm{MgH}_{2}+$ $\mathrm{Cu}$, occurs and stable hydride, $\mathrm{MgH}_{2}$, forms during hydrogenation. Thus, the region lying above the narrow band can be considered as the disproportionation reaction region.

In contrast, the alloys located in the region below this narrow band tend to form unstable hydrides. $\mathrm{YNi}_{5}$ is one such example, as its equilibrium pressure of hydrogen is very high. Therefore, this region can be considered as the hydride-unstable region. Following this naming, the disproportionation reaction region is the hydride-stable region, since the hydride in this region is so stable that the desorption process is hardly activated in such a region.

Here, as shown in figure 7 , the $\mathrm{Mg}-\mathrm{Ni}$ system has the largest bond order ratio among the alloys. This means that the $\mathrm{Mg}-\mathrm{Ni}$ bond is much stronger than the $\mathrm{Mg}-\mathrm{Mg}$ bond. This is the reason why disproportionation reaction does not take place despite the high $\mathrm{Mg} / \mathrm{Ni}$ compositional ratio in this system. On the other hand, in case of the $\mathrm{La}-\mathrm{Ni}$ system, the $\mathrm{La} / \mathrm{Ni}$ compositional ratio is low, since the $\mathrm{La}-\mathrm{La}$ bond is stronger than the La-Ni bond. Therefore, it is supposed that the disproportionation reaction will take place during the hydrogenation as the $\mathrm{La} / \mathrm{Ni}$ compositional ratio increases. However, even in a case the onset of the disproportionation reaction may be suppressed by controlling the bond order ratio in some ways. For example, by substitution of $\mathrm{Mg}$ atoms for $\mathrm{La}$ atoms in the La-Ni system may increase the average bond order ratio,

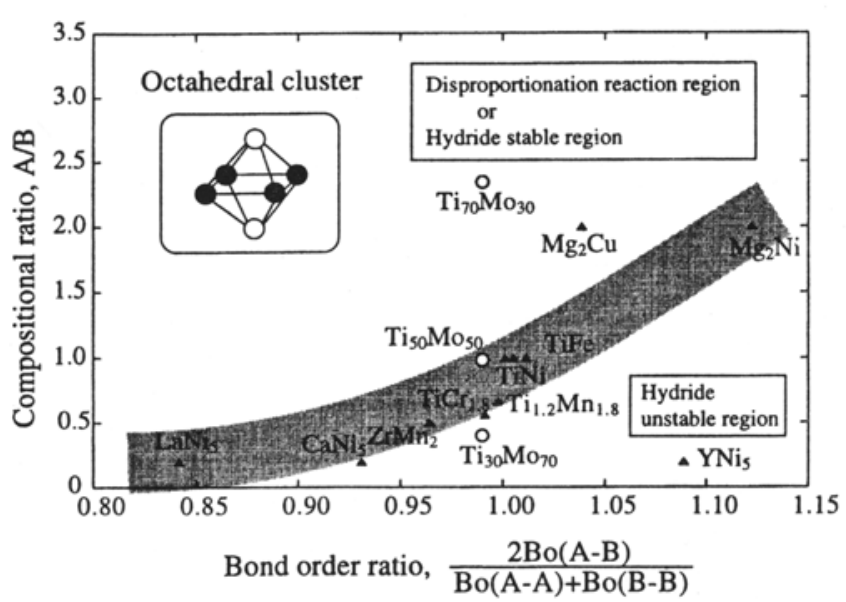

Figure 8. Correlation between the A/B compositional ratio and the bond order ratio for octahedral cluster. and hence the onset of the disproportionation reaction may be suppressed even in an alloy with relatively high La concentration.

Similar results are also obtained for the octahedral clusters, as shown in figure 8. Thus, the present result is independent of the clusters used for the calculation. Once $\mathrm{A}$ and $\mathrm{B}$ elements are chosen, the $\mathrm{A} / \mathrm{B}$ compositional ratio is determined following a relationship with the bond order ratio shown in figures 7 or 8 .

3.3c Application to disordered alloys: This approach is applicable even to the disordered alloys containing both $A$ and $B$ elements. As an example, the Ti-Mo system is chosen since there is a perfect solid solution in this system without forming any intermetallic compounds. From the calculation, using an octahedral cluster, the bond order ratio is estimated to be about 0.99 for Ti-Mo system. Then, for the convenience of the experiment explained later, three alloys, $\mathrm{Ti}_{30} \mathrm{Mo}_{70}, \mathrm{Ti}_{50} \mathrm{Mo}_{50}$, and $\mathrm{Ti}_{70} \mathrm{Mo}_{30}$ were selected and their location were plotted in figure 8. As is evident from this figure, $\mathrm{Ti}_{30} \mathrm{Mo}_{70}$ and $\mathrm{Ti}_{70} \mathrm{Mo}_{30}$ are located below and above the narrow band, respectively. This suggests that hydrogenation is difficult for the $\mathrm{Ti}_{30} \mathrm{Mo}_{70}$ alloy. Also, a certain disproportionation reaction may take place or a stable hydride may be formed in the $\mathrm{Ti}_{70} \mathrm{Mo}_{30}$ alloy. On the other hand, the $\mathrm{Ti}_{50} \mathrm{Mo}_{50}$ alloy lies on the narrow band. Thus, perhaps both the hydrogen absorption and desorption processes may get activated at moderate temperature only for the $\mathrm{Ti}_{50} \mathrm{Mo}_{50}$ alloy.

In order to confirm this interpretation, the hydriding and dehydriding properties of the Ti-Mo system were examined experimentally. The three alloys, $\mathrm{Ti}_{30} \mathrm{Mo}_{70}$, $\mathrm{Ti}_{50} \mathrm{Mo}_{50}$ and $\mathrm{Ti}_{70} \mathrm{Mo}_{30}$, were prepared by arc-melting and then homogenized at $1273 \mathrm{~K}$ for $86.4 \mathrm{ks}$. Subsequently, they were crashed mechanically into powders and used for the PCT measurement. The results of the PCT measurement at $313 \mathrm{~K}$ are given in figure 9. All the alloys show

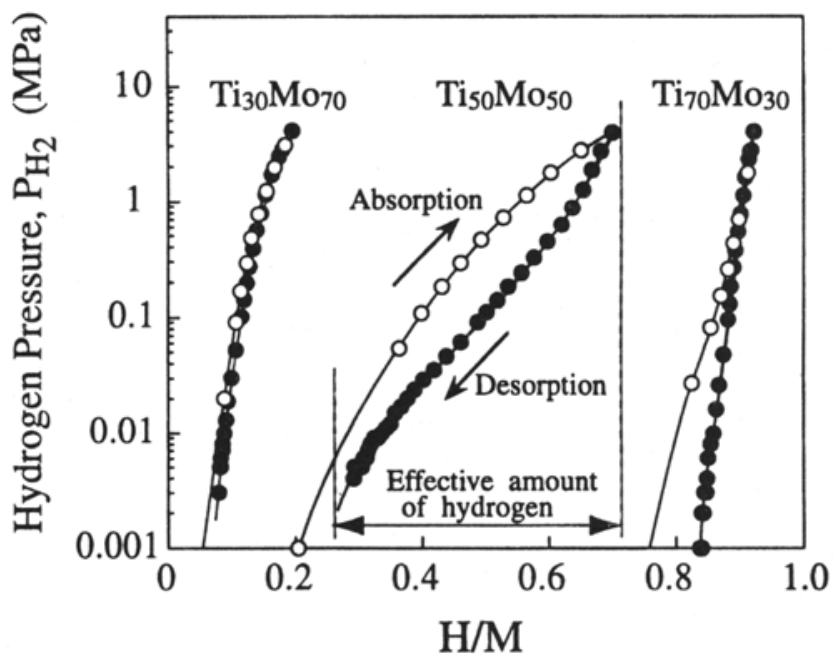

Figure 9. PCT diagram for Ti-Mo binary alloys at $313 \mathrm{~K}$. 
no plateau in the PCT diagram. This is one of the characteristics of the disordered alloy. However, there are noteworthy differences among the alloys. For example, the total amount of absorbed hydrogen increases with increasing the compositional ratio, Ti/Mo. A very stable hydride is formed in the $\mathrm{Ti}_{70} \mathrm{Mo}_{30}$ alloy so that it is hardly dehydrided and hence the amount of released hydrogen is very low in the desorption process. On the other hand, in case of the $\mathrm{Ti}_{30} \mathrm{Mo}_{70}$ alloy, hydrogen is scarcely absorbed in it. In contrast to these two alloys, the effective amount of hydrogen to be absorbed and released at $313 \mathrm{~K}$ is relatively large only in the $\mathrm{Ti}_{50} \mathrm{Mo}_{50}$ alloy. All these results are in good agreement with the results shown in figure 8.

\section{Conclusion}

An electronic approach is presented to the understanding of hydrogen storage alloys in a fundamental manner. From a series of the DV-X $\alpha$ molecular orbital calculations, the roles of hydride-forming and hydride-nonforming elements in the alloys is shown. Also, some criteria for alloy design (e.g. optimum alloy compositions) have been proposed in this study.

\section{Acknowledgements}

The authors would like to express sincere thanks to Messrs Y Takahashi, T Matsumura, $K$ Nakatsuka and $M$ Nakai, all the graduate students of Nagoya University, for their help in the DV-X $\alpha$ molecular orbital calculations. We also acknowledge the Computer Centre,
Institute for Molecular Science, Okazaki National Institute for the use of the SX-3/34R computer. This research was supported by the Grant-in-Aid for Scientific Research from the Ministry of Education, Science, Sports and Culture of Japan.

\section{References}

Adachi H, Tsukada M and Satoko C 1978 J. Phys. Soc. Japan 45874

Adachi H, Shiokawa S, Tsukada M, Satoko C and Sugano S 1979 J. Phys. Soc. Japan 471528

Matsumura T, Yukawa H and Morinaga M $1998 \mathrm{~J}$. Alloys Comp. 279192

Matsumura T, Yukawa H and Morinaga M $1999 \mathrm{~J}$. Alloys Comp. 28482

Morinaga M, Yukawa N and Adachi H 1984 J. Phys. Soc. Japan 53653

Morinaga M, Yukawa N and Adachi H 1985 J. Phys. F15, 1071

Morinaga M, Yukawa N, Adachi H and Mura T 1987 J. Phys. F17 2147

Mulliken R S 1955 J. Chem. Phys. 23 1833, 1841, 2338, 2343

Nakatsuka K, Yoshino M, Yukawa H and Morinaga M 1998 Proceedings of the international symposium on metal hydrogen system (MH-98) Hangzhou China, 1999

Takahashi Y, Yukawa H and Morinaga M 1996 J. Alloys Comp. 24298

Yukawa H and Morinaga M 1997 Advances in quantum chemistry, p. 83

Yukawa H, Takahashi Y and Morinaga M 1996 Intermetallics 4 S215

Yukawa H, Takahashi Y and Morinaga M 1999 Computational Mater Sci. 14291 